\title{
Mobile Learning Application to Facilitate Ubiquitous Collaborative Learning: An Organizational Behavior Course
}

\author{
Amr Swid \\ St. Edwards University \\ Hui-Yin Hsu \\ New York Institute of Technology \\ Shiang-Kwei Wang \\ New York Institute of Technology
}

This paper proposed further development of a recently created mobile learning app as a platform to facilitate graduate business major students' interaction and collaborative learning. The objectives of this app are 1) facilitate students' learning through ubiquitous approach, 2) facilitate social interaction among students and faculty, and 3) enhance learning motivation and develop cultural competence. The paper discusses the needs of the app development, describes the implementation and goals to improve the app design. Targeting students' learning with an App across global campuses will advance the knowledge in mobile learning in international organizational behavior course. This paper provides insights on the prototype based on these discussions and the instructional needs.

\section{INTRODUCTION}

Educators advocating the use of technology, especially mobile learning, articulate that digital natives who were born in the $21^{\text {st }}$ century have grown up in the technology-saturated environment. Moreover, they are used to social interaction through mobile devices (Aadone, Dron \& Pemberton, 2009; Tpscott, 2009, Duncan, 2013; Elmelegy \& Swid, 2013).

There are increasing college courses being offered through a learning management system (LMS), e.g., Edmodo, SuccessFactors, cornerstone, Moodle, and Blackboard. To respond to the learning interests of the incoming tech-savvy digital natives, the LMS has migrated to mobile devices.

Take Blackboard Mobile Learn app as an example; the students use their current Blackboard credentials to access their course materials, post comments and questions to various online forums, and to interact using communication tools on their mobile devices. However, the design of the Blackboard Mobile learning app cannot accommodate pedagogical practices needed in a course designed for students across global context. This article discusses our effort to enhance a newly created mobile app to enable college students to access learning materials and interact with classmates from global campuses in anytime, anywhere format. The App was designed for International Organization Behavior course by the 
first author. The following section will review the recent literature in this significant and emerging area of the technology use and the students' adaptation behavior for such technology.

\section{LITERATURE REVIEW}

While mobile phones' primary use was calling and texting, today almost $50 \%$ of students use their smartphones to access the internet (Donaldson, 2010). Research by Robin Donaldson (2010) investigated several factors like performance, effort, social influence, and facilitating conditions to understand college student's willingness to use mobile learning tools. The study identified facilitating conditions has a significant impact on the student's behavioral intentions to accept mobile learning tools (Donaldson, 2010). Facilitating conditions for college students include simple and easy usage of learning tools but also the fast and hassle-free connection to wireless connections (Caudill, 2007).

One cannot deny the importance of integrating the unique technological strength of mobile technology into any learning environment (Yu-Lin et al., 2010). Among a large number of features and advantages of mobile technology for students, mobile technology specifically for learning purposes provides two main elements: ubiquitous mobility and situated context (Yu-Lin et al., 2010). Ubiquitous mobility enables students to exercise their learning activities and habits anywhere and everywhere they go as well as connect to fellow peers globally (Yu-Lin et al., 2010; Sharples Beale, 2003; Joiner et al. 2006; Fallahkhair, 2007). Situated learning is considered the outcome of mobile learning and its functionality (Yu-Lin et al., 2010; Hall \& Bannon, 2006; Morkon et al., 2007). Situated learning can be explained as the how students can find the suitable examples for their learning experience and understand it (Yu-Lin et al., 2010).

For this course, International Organizational Behavior' situated learning treats symbolic cultural information processing as fundamental to learning, and the view of situated nature of knowledge as significant because it focuses primarily on behavioral and cognitive aspects of individual learning in a global environment using mobile technology.

Mobile technology and applications have become the new trend that would enable students to explore new information at all times while being mobile, as well as finding similar examples online as they go through the learning experience.

The primary function of Blackboard LMS is to facilitate instructors to organize and present materials, facilitate discussion and allow students to access content and interact through discussion forums. Blackboard has its limitations regarding enabling instructors to adopt particular pedagogical practices to support students' learning. Kinash, Brand, and Mathew (2012) studied 135 college students to investigate if using Blackboard Mobile Learn had any impact on their learning. The results revealed that most students did not find any difference between using Blackboard Mobile Learn or using a PC to access to Blackboard learning content (Kinash, Brand \& Mathew, 2012). These results agree with several other studies (Blin \& Munro, 2008; Cochrane \& Bateman, 2010; Wang, Hsu, Reeves \& Coster, 2014) which indicated that the additional use of technology does not alter the nature of learning. To fully utilize the unique functions of a specific technology, appropriate pedagogies must be adapted to meet students' learning needs.

\section{THE CONCEPTUAL MODEL FOR THE APP}

MGMT 620 or "International Dimensions of Organizational Behavior" is a graduate level course designed to help students understand the global cultural framework, effective communication and motivation across cultures, leadership in multicultural environment, managing diversity, conflicts, and ethics. This course is offered at a four-year institution in the northeastern U.S. which has multiple campuses, including Abu Dhabi, China, and Canada. The course aims to equip the students with the knowledge, abilities, and skills to understand organizational behaviors in the global context. The instructor has been exploring opportunities to engage students to interact with other global campuses through the deployment of technology. Therefore, a platform is needed to facilitate students' interaction, 
collaboration and situated case study across numerous campuses. While Blackboard Mobile Learn allows students to access multimedia materials, participate in the discussion, and check their learning progress, it does not allow the instructor to customize and build a situated learning community and experiential learning materials that enables ubiquitous learning. For example, it is not supported for feedback by the grader for individual questions, and do not allow new submission attempts and posts.

To meet the instructional needs, the instructor worked with two education experts to develop the mobile-based learning activities, and propose a platform to that can support unique learning needs and facilitate these pedagogical practices:

- Facilitate students' cultural awareness and competence through real-time interaction with classmates in another global campus.

- Allow instructors or students to invite a guest speaker who is not a registered user to interact with the class synchronously and asynchronously.

- Allow instructors to enable discussion and exchange of situated and local cases generated by groups of students from two or more different campuses worldwide.

- Allow students to create and share multimedia case studies instantly for discussion. For instance, students could interview a company leader using a mobile device and upload audio or video files (with permission) for discussion immediately or record their scenario on organizational decision making for discussion.

- Blackboard app has limited support for the instructor's needs (too stagnant, not dynamic), while a mobile App. Could facilitate real-time engagement.

- The app can integrate elements to support social interaction and social learning (e.g., group discussion board)

- Connect students from multiple sections and campuses.

- Accommodate digital natives' technology preference.

The purpose of this platform is not to replace the use of Blackboard. It is designed as a supplementary tool to enable a variety of pedagogical practices and to facilitate students' interaction and to learn among global campuses. Any instructors who adopt this platform can design several projects and have students complete these projects using this app.

\section{App. Structure/Technical Requirement}

The design blueprint and structure of the App (MGMT620) was developed by the instructor. He used a self-doing platform for creating content-based native mobile apps for Android and iPhone. It runs inside a browser on user's devices. Provide instant cross-platform support, no installation required. The App is available at Google play store at https://play.google.com/store/search?q=Management $\% 20620 \% 20$ $\underline{(\mathrm{NYIT}) \& \mathrm{c}=\text { apps\&hl}=\mathrm{en}}$

Contents can be downloaded and viewed at http://h.studentsapp.mobi/index.php?app=mgmt620. The prototype of the app "packaged" the web content and can be distributed through app stores and run offline. The instructor tested the prototype with groups of students and collected their feedback informally. The preliminary implication result demonstrated that this app allows the instructor to enable diversified pedagogical practices to get the students more involved with a global perspective of organizational behavior topics, e.g., culture. It allows students from multiple campuses to interact and exchange case studies in a real-time format and facilitate students' learning outcomes in the following ways: engagement, attitude, and collaboration of the case studies, feedback and sharing experience from the students and faculty. Students had provided their feedback on the implementation. They thought that the learning app is an excellent addition to Blackboard Learn because it helps them "understand concepts and share additional insights through the app that were beneficial for the practical implications of course." They also expressed the challenges of using Blackboard Learn, most of the time it gives them a hard time to access the app, and it doesn't always show the updates for the course. This app is customized to meet the instructor's needs regarding scope and sequence of learning and facilitate of interaction. The app breaks each part down, which makes it easier to navigate and understand the content and conduct learning 
activities. Therefore, more features can be added in the next version to enhance the function of the app. New features will include:

- Unique user login name and password for both users - students and faculty

- App has to be web based and download version for offline use

- Cross Platform: user experience has to be seamless with different versions

- For download version, the OS to be supported are iOS \& Android

- Language - Support for language localization

- Minimum language interface for global acceptance

- Design to capture data for both quantitative and qualitative inputs:

a. Core responses to direct questions

b. Students give ratings for a specific course/faculty

\section{Implications}

This paper is to establish a position to advocate ubiquitous and situated learning in global organizational behavior and stimulate conversations to advance our knowledge in situated learning in organizational behavior in global contexts. Further, the paper provides insights on the design and applications of a prototype designed based on these discussions. This app could be adopted by any faculty who are interested in having students experience unique pedagogical practices on mobile devices.

\section{Future Research}

Students' use of technology and smartphones for learning and education purposes is still an underdeveloped subject that needs more time and effort by both faculty and students to experience the wonderful implications of seamless mobile learning tools. Research proposal to further investigate how this app could be enhanced to match digital natives learning preference and customized to fit faculty and students' learning needs.

\section{REFERENCES}

Andone, D., Dron, J. \& Pemberton, L. (2009). Developing a desirable learning environment for digital students. Technology, Instruction, Cognition, and Learning, 6(4), 253-271. [verified 27 Apr 2012] http://idt7895.files.wordpress.com/2009/05/developing-a-desirable-learningenvironmentfor-digital-students.pdf

Blin, F., \& Munro, M. (2008). Why hasn't technology disrupted academics' teaching practices? Understanding resistance to change through the lens of activity theory. Computers \& Education, 50(2), 475-490. http://dx.doi.org/10.1016/j.compedu.2007.09.017

ElMliegy, A. \& Swid A. (2013). Managing User Acceptance and Use of Technology in Higher Education: An Empirical Study. Management Education: An International Journal, 12(1), 11-23.

Caudill, J. G. (2007). The growth of m-Learning and the growth of mobile computing: Parallel developments. International Review of Research in Open and Distance Learning, 8(2).

Cochrane, T., \& Bateman, R. (2010). Smartphones give you wings: Pedagogical affordances of mobile Web 2.0. Australasian Journal of Educational Technology, 26(1), 1-14. http://www.ascilite.org.au/ajet/ajet26/cochrane.html

Donaldson, R. L. (2010). Student acceptance of mobile learning (Order No. 3483638). Available from ProQuest Central. (902631958). Retrieved from http://arktos.nyit.edu/login?url=https://search.proquest.com/docview/902631958?accountid=1291 7

Duncan N.G., Dufrene B.A., Sterling, H.E., Tingstrom, D.H. (2013). Promoting teachers' generalization of intervention use through goal setting and performance feedback. Journal of Behavioral Education, 22 (4), 325-347. http://dx.doi.org/10.1007/s10864-013-9173-5 
Fallahkhair, S., Pemberton, L., \& Griffiths, R. (2007). Development of a cross-platform ubiquitous language learning service via mobile phone and interactive television. Journal of Computer Assisted Learning, 23, 312-325.

Hall, T., \& Bannon, L. (2006). Designing ubiquitous computing to enhance children's learning in museums. Journal of Computer Assisted Learning, 22, 231-243.

Joiner, R., Nethercott, J., Hull, R., \& Reid, J. (2006). Designing educational experiences using ubiquitous technology. Computers in Human Behavior, 22, 67-76.

Kinash, S., Brand, J. \& Mathew, T. (2012). Challenging mobile learning discourse through research: Student perceptions of Blackboard Mobile Learn and iPads. Australasian Journal of Educational Technology, 28(4), 639-655.

Morken, E. M., Divitini, M., \& Haugaløkken, O. K. (2007). Enriching spaces in practice-based education to support collaboration while mobile: the case of teacher education. Journal of Computer Assisted Learning, 23, 300-311.

Tapscott, D. (2009). Grown up digital. New York: McGraw Hill.

Wang, S.-K., Hsu, H.-Y., Reeves, T. C. \& Coster, D. C. (2014). Professional development to enhance teachers' practices in using information and communication technologies (ICTs) as cognitive tools: Lesson learned from a design-based research study. Computers \& Education, 79, 101-115.

Yu-Lin, J., Ting-Ting, W., Yueh-Min, H., Tan, Q., \& Yang, S. J. H. (2010). The add-on impact of mobile applications in learning strategies: A review study. Journal of Educational Technology \& Society, 13(3). 3-n/a. Retrieved from

http://arktos.nyit.edu/login?url=https://search.proquest.com/docview/1287037262?accountid=129 17 